This item was submitted to Loughborough's Research Repository by the author.

Items in Figshare are protected by copyright, with all rights reserved, unless otherwise indicated.

\title{
Better vehicle design for all
}

PLEASE CITE THE PUBLISHED VERSION

http://dx.doi.org/10.1201/b16742-73

PUBLISHER

CRC Press (@ Taylor and Francis)

VERSION

AM (Accepted Manuscript)

LICENCE

CC BY-NC-ND 4.0

REPOSITORY RECORD

Karali, Sukru, Diane E. Gyi, and Neil J. Mansfield. 2019. "Better Vehicle Design for All". figshare. https://hdl.handle.net/2134/14495. 
This item was submitted to Loughborough's Institutional Repository (https://dspace.lboro.ac.uk/) by the author and is made available under the following Creative Commons Licence conditions.

\section{creative
commons}

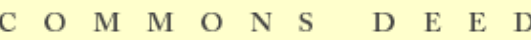

Attribution-NonCommercial-NoDerivs 2.5

You are free:

- to copy, distribute, display, and perform the work

Under the following conditions:

Attribution. You must attribute the work in the manner specified b the author or licensor.

Noncommercial. You may not use this work for commercial purposes.

No Derivative Works. You may not alter, transform, or build upon this work.

- For any reuse or distribution, you must make clear to others the license terms of this work.

- Any of these conditions can be waived if you get permission from the copyright holder.

Your fair use and other rights are in no way affected by the above.

This is a human-readable summary of the Leqal Code (the full license).

\section{Disclaimer 만}

For the full text of this licence, please go to: http://creativecommons.org/licenses/by-nc-nd/2.5/ 
In: Contemporary Ergonomics and Human Factors 2014. Editors: Sarah Sharples and Steven Shorrock. Taylor and Francis, ISBN 978-1-138-02635-3, pages 413-416.

\title{
BETTER VEHICLE DESIGN FOR ALL
}

\author{
Sukru Karali, Diane Gyi, Neil Mansfield
}

Loughborough University

Loughborough Design School

\begin{abstract}
With increases in life expectancy, there is a growing population of older people around the world. As a result, the population of older drivers is showing a similar increase. Many cars have not been designed to meet the needs of people with age-related disabilities. A questionnaire survey of older and younger drivers (paper/online version $n=903$ ) and supplementary interviews with drivers aged $\geq 65$ years $(n=15)$ were conducted June-August 2012. Younger drivers were identified as $<65$ years $(53.5 \%)$ and older drivers were $\geq 65$ years (46.5\%). $7.1 \%$ of participants were aged $\geq 80$. Older males and females reported more difficulties with parallel parking and driving on a foggy day than younger drivers. Significantly more discomfort was reported by older drivers in the hips, thighs, buttocks and knees compared to younger drivers.
\end{abstract}

\section{Introduction}

Vehicle design and performance are constantly being developed with vehicles becoming smarter and more sophisticated. Contemporary vehicles are now equipped with many characteristics formerly constrained to the luxury market: for example, technologies to assist the user with specific driving tasks such as intelligent automated parking systems (Bradley et al., 2008). There is a growing population of older people around the world, mainly in developed countries (Meyer, 2009). According to 2012 figures of DVLA there are more than 15 million people aged over 60 with a driving license; more than 1 million of those are over 80 (IAM, 2012). However, the automotive industry has not focused on the needs and expectations of this population and many cars do not meet the needs of people with age-related disabilities (Herriotts, 2005). On the other hand, all vehicle manufacturers claim to provide a positive driving experience, but do they really meet the requirements of users of all ages? 


\section{Methodology}

A comprehensive questionnaire survey was conducted within the UK with a large sample of car drivers. In total 903 people took part; 53.5\% were younger drivers $(n=483,<65)$ and $46.5 \%$ were older drivers $(n=420, \geq 65)$. Drivers over 80 years represented $7.1 \%(n=64)$ of the whole sample. $59 \%$ of participants were male and $41 \%$ were female (Table 1). The aim was to understand the experiences of car drivers of different ages and identify some of the key challenges for car design. The questionnaire was available as both paper and online versions and included: musculoskeletal symptoms, the vehicle seat, access to specific vehicle features, driving performance and driving behavior.

\begin{tabular}{llllllll}
\hline Age category & Age & \multicolumn{2}{c}{ Male } & \multicolumn{3}{c}{ Female } & \multicolumn{3}{c}{ Total } \\
& & $\mathrm{n}$ & $\%$ & $\mathrm{n}$ & $\%$ & $\mathrm{n}$ & $\%$ \\
\hline Younger drivers $(<65$ & $20-34$ & 70 & 7.8 & 66 & 7.3 & 136 & 15.1 \\
years $53.5 \%$ & $35-49$ & 62 & 6.9 & 53 & 5.9 & 115 & 12.7 \\
& $50-64$ & 144 & 15.9 & 88 & 9.7 & 232 & 25.7 \\
\hline Older drivers $(\geq 65$ years $)$ & $65-79$ & 216 & 23.9 & 140 & 15.5 & 356 & 39.4 \\
$46.5 \%$ & $\geq 80$ & 43 & 4.8 & 21 & 2.3 & 64 & 7.1 \\
\hline Total & & 535 & 59.2 & 368 & 40.8 & 903 & 100
\end{tabular}

Table 1: Age and gender distribution (whole sample)

Many factors were considered during the design and development of the survey, for example, questions had to be to be specific, short and easy to read/understand for older people. Questions from a survey conducted by Sang et al. (2009) were included in this survey with slight modifications. Where appropriate, Likert scales were incorporated with specific statements and tick boxes.

A stratified sampling technique was used, whereby the population is divided into various subgroups/strata (Robson 2012). Once the strata are determined, a simple random sample was taken from each stratum individually. For the questionnaire survey, the sample was arranged in a number of sub-groups focusing on age and gender.

Major organisations within the UK were consulted for distribution of the questionnaire to the target audience. These are well known institutes, voluntary action groups, and charity and motoring organisations. Agreement was obtained for the distribution of questionnaire (data collection from e-mails, interviews and personal contacts). For the on-line survey several techniques were used to increase the number of responses such as; snowballing technique. Initially, the target sample size for the survey was 600; this was thought to be a reasonable number in order gain a robust data set for statistical analysis; however, the survey achieved $50 \%$ more $(n=903)$. Supplementary interviews $(n=15)$ were 
conducted with a further sample of drivers aged 65 years and over by using the questionnaire in a structured interview format.

\section{Results}

Musculoskeletal symptoms: high levels of musculoskeletal symptoms were reported in the lower back, knees, neck, shoulders and elbows. Younger drivers reported higher levels of musculoskeletal symptoms in the neck $(p<0.01)$, shoulders $(p<0.05)$ and middle back $(p<0.001)$, than older drivers. These symptoms are likely to be related to their level of activity (e.g. work) compared to older drivers. Significantly more discomfort was reported by older drivers in the hips/thighs/buttocks and knees $(p<0.05)$ compared to younger drivers.

Driving behaviour: half of all respondents (46.7\%) reported that other drivers' lights restricted their vision when driving at night; more females $(53.3 \%)$ than males $(42.5 \%)$ reported this $(p<0.001$; Table 2$)$. Older drivers $(31.7 \%)$ reported more difficulties than younger drivers $(18.4 \%)$ with turning their head and body around during reversing $(p<0.001)$. Similarly, older drivers reported their reactions were slower than they used to be (e.g. braking in an emergency situations) compared to younger drivers.

\begin{tabular}{llll}
\hline Answer options & $\begin{array}{l}\text { Agree } \\
(\%)\end{array}$ & $\begin{array}{l}\text { Neither agree } \\
\text { or Disagree } \\
(\%)\end{array}$ & $\begin{array}{l}\text { Disagree } \\
(\%)\end{array}$ \\
\hline $\begin{array}{l}\text { Other drivers' lights restrict my vision when } \\
\text { driving at night }\end{array}$ & 46.7 & 19 & 34.2 \\
\hline $\begin{array}{l}\text { I have difficulty turning my hand and body } \\
\text { around when reversing }\end{array}$ & 24.5 & 14.2 & 61.4 \\
\hline $\begin{array}{l}\text { Operating entertainment systems distract me } \\
\text { from driving (e.g. playing radio) }\end{array}$ & 23.7 & 38 & 38.3 \\
\hline $\begin{array}{l}\text { Operating navigation systems distract me from } \\
\text { driving (e.g. looking at sat-navigation) }\end{array}$ & 22.9 & 29.5 & 56.9 \\
\hline $\begin{array}{l}\text { My reactions are slower than they used to be } \\
\text { (e.g. braking in an emergency situation) }\end{array}$ & 22.8 & 20.3 & \\
\hline
\end{tabular}

Table 2: Driving behaviour (whole sample)

Driving performance: older males and females (16.8\%) reported more difficulties with parallel parking and driving on a foggy day than younger $(12.2 \%)$ drivers $(p<0.01)$. Compared to younger drivers $(25.5 \%)$, older drivers $(19.5 \%)$ reported having less distraction when using navigation systems but no significance was found. Reasons for this may include that older drivers are more experienced and they know the routes. They also tend to travel shorter distances and therefore they are less likely to use these technologies compared to younger drivers. 
Adjusting the seat features: $10.5 \%$ of respondents reported that they were dissatisfied with adjusting specific seat features, namely the head rest height, head rest distance from the head and setting the seat belt height. Females reported more difficulty than males. Reasons given for this difficulty may include reaching, accessing and operating the controls while seated.

Supplementary interviews: the main findings are summarized as follows:

- Females (specifically older females) reported more difficulty than males with adjusting seat features, namely the head rest height/distance and seat belt height. Reasons given for this include reaching, accessing and operating the controls while seated.

- When reaching and pulling the boot door down to close, older females reported having less mobility and reduced reach. A reason may be that older females are shorter in stature.

- Older drivers are less likely to drive at night.

- Older drivers generally avoid using navigation systems due to their short travelling distances.

- The most commonly used entertainment system is the radio among older drivers.

\section{Conclusion}

This study has provided data to understand the key issues experienced by drivers of all ages. Some issues are common for all ages, and some are age related. The future direction of this research will focus on understanding how design of the vehicle cab impacts on posture, comfort, health and wellbeing in older drivers.

\section{References}

BRADLEY, M., KEITH, S., KOLAR, I., WICKS, C., GOODWIN, R., 2008. What do older drivers want from new technologies? [online]. SPARC, Reading. [viewed 12/01/2012]. Available from: http://www.sparc.ac.uk/media/downloads/executivesummaries/execsummary bradley.pdf

HERRIOTTS, P., 2005. Identification of vehicle design requirements for older drivers. Applied Ergonomics, 36(3), pp. 255-262.

IAM, 2012. More than a million drivers now aged over 80. [online]. Institute of Advanced Motorists, London. [viewed 22/05/2012]. Available from: http://www.iam.org.uk/news/latest-news/983-more-than-a-million-driversnow -aged-over-80 
MEYER, J., 2009. Designing in-vehicle technologies for older drivers. [online]. National Academy of Engineering, Washington. [viewed 20/01/2012]. Available from http://www.nae.edu/About/19687.aspx

SANG, K., GYI, D. and HASLAM, C., 2009. Musculoskeletal symptoms in pharmaceutical sales representatives. Occupational Medicine, 60(2), pp.108114. 